\title{
Comparison of the Efficacy of the Various Treatment Modalities in the Management of Perianal Crohn's Fistula: A Review
}

\author{
Shah Huzaifa Feroz ${ }^{1,2}$, Asma Ahmed ${ }^{3}$, Abilash Muralidharan ${ }^{4}$, Pragatheeshwar Thirunavukarasu ${ }^{5}$ \\ 1. General Surgery, Jawaharlal Nehru Medical College, Aligarh, IND 2. General Surgery, Larkin Community Hospital, \\ Miami, USA 3. General Surgery, Ramaiah Medical College and Hospital, Bangalore, IND 4. Internal Medicine, Kiruba \\ Hospital, Coimbatore, IND 5. Surgical Oncology, Cancer Treatment Centers of America, Tulsa, USA
}

Corresponding author: Shah Huzaifa Feroz, drhuzaifa@protonmail.com

\begin{abstract}
Crohn's disease (CD) is a transmural inflammatory bowel disease (IBD) that can affect any part of the gastrointestinal (GI) tract. With the disease's progression, adhesions and transmural fissuring, intraabdominal abscesses, and fistula tracts may develop. An anal fistula (or fistula-in-ano) is a chronic abnormal epithelial lined tract communicating the anorectal lumen (internal opening) to the perineal or buttock skin (external opening). The risk of fistula development varies from 14\%-38\%. It can cause significant morbidity, which adversely impacts the quality of life. It is mostly believed that an anal crypt gland infection causes anal abscesses, leading to fistula development. Crohn's disease's pathogenesis involves Th1 and Th17 hypersensitivity due to an unknown antigen within the intestinal mucosa.
\end{abstract}

Evidence to support this review was gathered via the Pubmed database. Search terms used were combinations of "Perianal fistula," "seton," "immunotherapy." Studies were reviewed and cross-referenced for additional reports.

Setons are surgical thread loops passed from the external to the internal opening of the fistula tract and exteriorized through the anorectal canal, facilitating abscess drainage and inciting a local inflammatory reaction, thus promoting the resolution of the fistula. Biologicals such as anti-tumor necrosis factor (TNF) antibody (infliximab, adalimumab, certolizumab), anti-IL-12/23 (ustekinumab), and anti- $\alpha_{4} \beta_{7}$ integrin antibody (vedolizumab) have been approved for Crohn's disease targeting the Th1/Th17-mediated inflammation. Other therapeutic modalities are fistulotomy, cyanoacrylate glue, bioprosthetic plugs, mucosal advancement flap, ligation of inter-sphincteric fistula tract (LIFT), diverting stoma, proctectomy, video-assisted anal fistula treatment (VAAFT), and fistula laser closure (FiLaC).

Review began 11/11/2020 Review ended 12/01/2020 Published 12/03/2020

\section{(c) Copyright 2020}

Feroz et al. This is an open access article distributed under the terms of the Creative Commons Attribution License CC-BY 4.0., which permits unrestricted use, distribution, and reproduction in any medium, provided the original author and source are credited.
Our review found that chronic seton therapy should be the primary approach, especially if the patient has a perianal abscess. It has a low incidence of re-intervention, recurrent abscess formation, and side-branching of the fistulous tract, with preservation of the fistulous tract's patency and cost-effectiveness. The major disadvantage of seton therapy is the discomfort and time to achieve stability. Among the biologicals, infliximab is the only therapy which has a statistically significant effect on the healing rate of perianal Crohn's fistula compared to placebo, but the major disadvantage associated with anti-TNF as sole therapy is high re-intervention rate, prolong maintenance therapy, high recurrence rate, and severe side effects. We hypothesize that the two aspects should be addressed concurrently to increase the fistula healing or closure rate. First, the seton should be used as initial therapy to maintain tract patency to allow abscess drainage and minimize the intestinal flora colonization within the tract mucosa, thereby leukocytic infiltration and propagation of inflammation within the tract. The second aspect that has to be considered is that we should target the initial stimulation of the Th1/Th17 mediated hypersensitivity instead of a factor/cytokine involved in the inflammation mediation. Although the unknown antigen triggering such hypersensitivity is not clear, we could target the RAR-related orphan receptor $\mathrm{Y}$ (RORY)-T (transcription factor involved in activation of Th17 cells) and the T-bet (transcription factor involved in activation of Th17 cells) within the GI mucosa by a novel target immune therapy.

Categories: Pathology, Allergy/Immunology, General Surgery

Keywords: perianal fistula, crohn's disease, seton, biologicals, infliximab, vedolizumab, fistulotomy, ustekinumab

\section{Introduction And Background}

The doctrine of fistula-in-ano treatment is to close the fistula tract without compromising continence [1]. The data from the National Health Interview Survey (NHIS) in 2015 revealed an estimated 3.1 million, or $1.3 \%$, of US adults have inflammatory bowel disease (IBD), with a significant increase in prevalence and hospitalization rate from 1999 [2,3,4]. The prevalence also differed significantly among several sociodemographic factors [2]. The mean hospitalization costs were $\$ 11,345$ for Crohn's disease (CD). It increased annually by 3\% from 2003 to 2008, although unchanged between 2008 to 2014 [5]. 
In 2017 , it was estimated that there were $~ 76,600$ prevalent cases and $\sim 15,700$ incident cases of fistulizing CD in the US, with varying distribution according to the fistula type. $11.7 \%$ of US individuals with CD have fistulizing $\mathrm{CD}$ at a given time (8.1\% anal, $1.1 \%$ rectovaginal, $0.3 \%$ enterocutaneous, and $2.2 \%$ internal of the Crohn's population) [6]. After one year of diagnosis, the cumulative incidence of fistulas was $21 \%$, while $50 \%$ after 20 years of diagnosis [6]. It is estimated that $~ 75 \%$ of anal fistulas in the CD population are complex $[7,8]$.

$\mathrm{CD}$ is a transmural IBD that can affect any part of the gastrointestinal (GI) tract from the mouth to the anus, but most commonly involves terminal ileum. It exhibits bimodal distribution first peak between the second and third decade and the second peak between the sixth and seventh decade. Three distinct patterns of disease are seen, i.e., inflammatory, stricturing, and perforating. With the disease's progression, adhesions and transmural fissuring, intra-abdominal abscesses, and fistula tracts may develop. An anal fistula (or fistula-in-ano) is a chronic abnormal epithelial lined tract (may also have granulation tissue) communicating the anorectal lumen (internal opening) to the perineal or buttock skin (external opening) and rarely to the vagina (in women) [9]. The lifetime risk of fistula development in patients with $\mathrm{CD}$ ranges from $14 \%$ to $38 \%$ [10]. The perianal fistulizing Crohn's disease can cause pain, purulent discharge, and destruction of the sphincter and perineal tissue, resulting in a significant adverse effect on the quality of life [11], and is a predictor of poor long-term outcomes [12]. It is mostly believed that anal abscess caused by an anal crypt gland infection leads to the suppuration into the inter-sphincteric space, forming an abscess, leading to fistula development (Figure 1) [13].

Anal crypt gland infection $\rightarrow$ Inter-sphincteric space infection $\rightarrow$ Anal abscess $\rightarrow$ Fistula

FIGURE 1: The sequence of events leading to perianal fistula formation

The pathogenesis of Crohn's disease involves Th1 and Th17 hypersensitivity due to an unknown antigen (possibly enteric floral antigens) within the intestinal mucosa. Increased production of transforming growth factor- $\beta$ (TGF- $\beta$ ) and Interleukin- 6 (IL-6) is responsible for the commitment of naive T-helper cells (Th0 cells) to Th17 cells, while IL-12 is required for differentiation of a Th0 cell into a Th1 cell. The production of IL-21 and IL-23 is responsible for the maintenance and expansion of the Th17 cells, while tumor necrosis factor (TNF) mediates the inflammation [14]. In the inflammatory infiltrate, IL-12, TNF, and IL-13 induce epithelial-to-mesenchymal transition and upregulation of matrix metalloproteinases, leading to tissue remodeling and fistula formation [15].

\section{Classifications of perianal fistula}

Park's fistula classification [16] is based on the fistula's relation to the external sphincter muscle and is a more anatomically precise classification (Table 1, Figure 2). The American Gastroenterological Association (AGA) Classification [17] for perianal fistulas is based on the complexity (Table 2), and is widely used as an empirical classification and includes a physical examination of the perianal area. Classification of the fistula based on four types, based on the relation of the fistula to the sphincter muscle; aka Park's Classification)

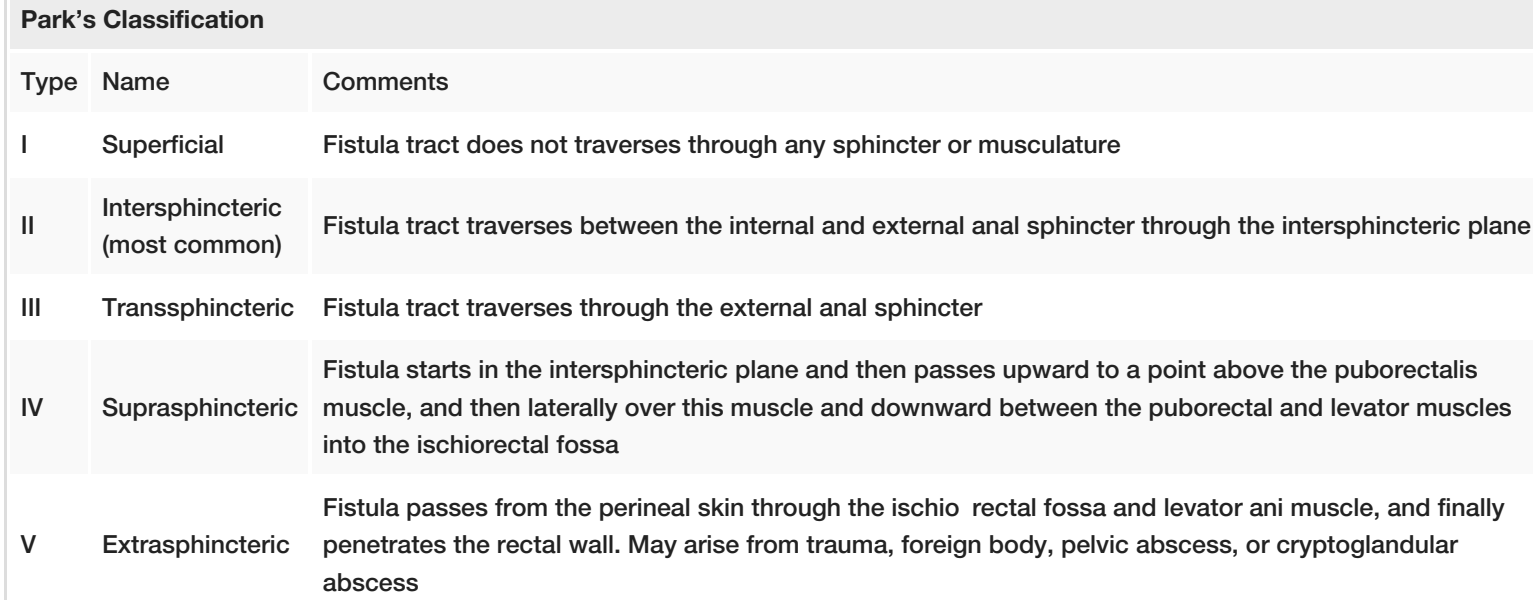

TABLE 1: Park's Classification 


\section{Cureus}

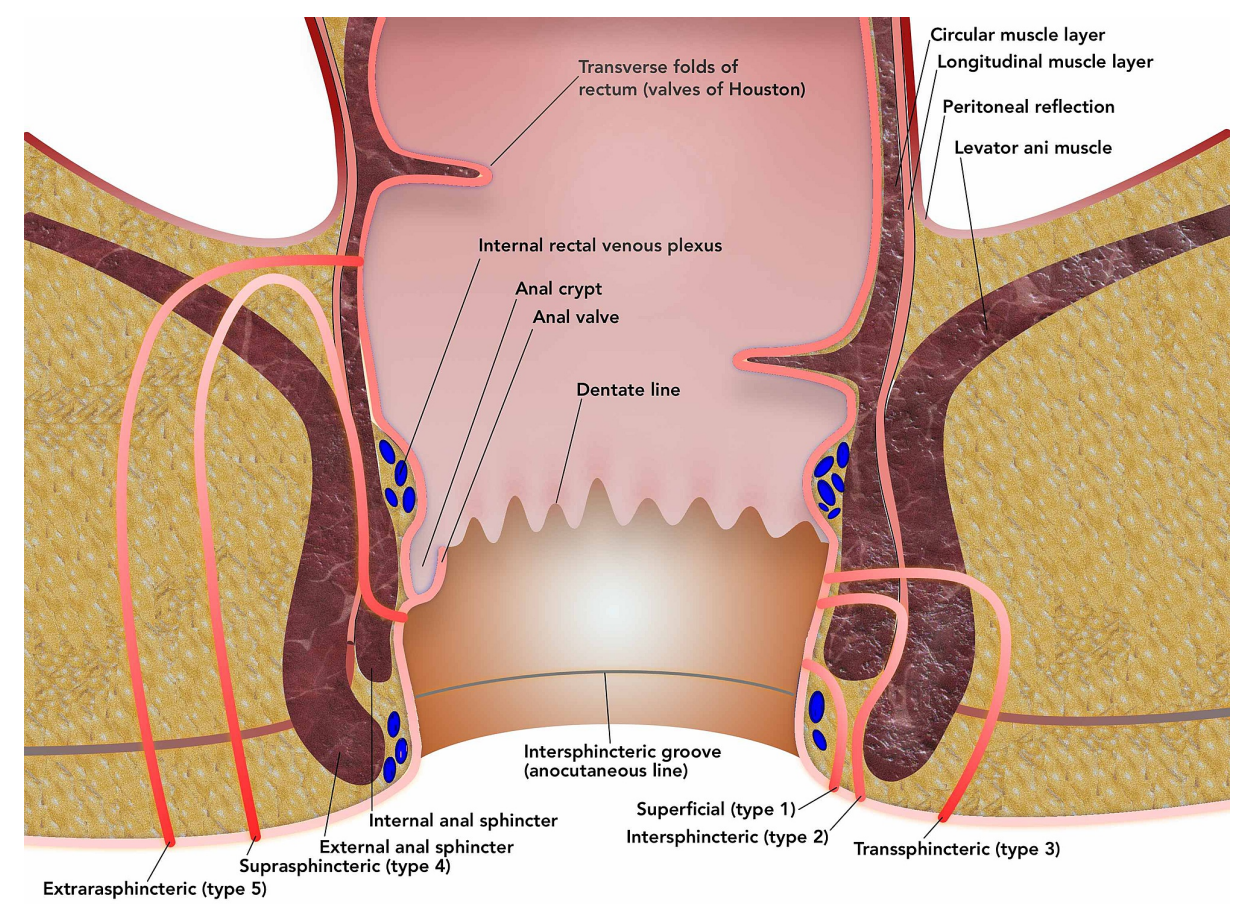

FIGURE 2: Park's Classification

American Gastroenterological Association's (AGA) Classification

Simple

Single external opening

No pain or fluctuation to suggest perianal abscess

Low (superficial or low intersphincteric or low transsphincteric origin of the fistula tract) with:
No evidence of a rectovaginal fistula

No evidence of anorectal stricture.

The presence of active rectal Crohn's disease may make a simple fistula more complicated to manage.
Complex

High (high intersphincteric or high transsphincteric or extrasphincteric or suprasphincteric origin of the fistula tract)

May have multiple external openings

May be associated with the presence of pain or fluctuation to suggest a perianal abscess

May be associated with the presence of a rectovaginal fistula

May be associated with the presence of an anorectal stricture

May be associated with the presence of active rectal disease at endoscopy

TABLE 2: American Gastroenterological Association's (AGA) Classification [17]

Setons are surgical thread loops passed from the external to the internal opening of the fistula tract and exteriorized through the anorectal canal, facilitating abscess drainage and inciting a local inflammatory reaction [18], thus promoting the resolution of the fistula. Surgeons usually prefer setons when the patient has a concomitant perianal abscess since it also allows incision and drainage. In addition, antibiotics (metronidazole or ciprofloxacin) are also supplemented, which further promotes healing [15].

The biologicals, e.g., anti-TNF antibody (infliximab, adalimumab, certolizumab), anti-IL-12/23 (ustekinumab), and anti- $\alpha_{4} \beta_{7}$ integrin antibody (vedolizumab) have been approved for Crohn's disease targeting the Th1/Th17 mediated inflammation and the diapedesis of the leukocytes in the intestinal mucosa respectively. With superficial and low inter-sphincteric fistulas, fistulotomy is often the choice, especially in the absence of active proctitis and a failed antibiotic therapy or any local therapy. Other modalities to manage the perianal Crohn's fistula are cyanoacrylate glue, bioprosthetic plugs, mucosal 
advancement flap, ligation of inter-sphincteric fistula tract (LIFT), diverting stoma, proctectomy, videoassisted anal fistula treatment (VAAFT), and fistula laser closure (FiLaC) [15].

\section{Review}

\section{Methods}

Evidence to support this review was collected via the Pubmed database. Search terms used were combinations of "Perianal fistula," "seton," "immunotherapy." Studies discussing the different modalities of management underpinning perianal fistula, especially in Crohn's disease, were reviewed and crossreferenced for additional reports. Table 3 depicts the keywords used and the number of articles found on the PubMed database with a filter of the 20 -year publication date and human studies. All the data were collected after a meticulous review of the articles.

\begin{tabular}{|c|c|c|}
\hline Keyword & Database & Number of articles \\
\hline Perianal fistula & PubMed & 1673 \\
\hline Perianal fistua seton & PubMed & 178 \\
\hline Perianal fistua seton biologicals & PubMed & 33 \\
\hline
\end{tabular}

TABLE 3: Number of articles found on the PubMed Database related to our Keywords

\section{Discussion}

Seton Placement

Setons have been considered the mainstay of surgical management for most fistulae-in-ano. There are mainly two techniques for seton placement based on the knot's tightness and the cutting nature. The first is the cutting or tight seton technique, in which a non-absorbable thread is inserted into the fistula tract and exteriorized through the anorectal canal, which incites inflammation and fibrosis. The setons are subsequently tightened, causing gradual, controlled cutting of the sphincter (staged fistulotomy) while allowing the reactive fibrosis to occur, ensuring the sphincter integrity [19].

In a study done by Raslan et al. with 28 patients with complex perianal Crohn's fistula, a $90.2 \%$ healing rate was noted by the end of the study (one year), with a recurrence rate of $9.8 \%$. A direct correlation between the healing time and the distance from the anal verge was also observed [13]. There have been many studies indicating complications associated with this technique, including prolonged perianal pain and incontinence. Although the rate of the incontinence associated varied, some reported minor damage $15.7 \%$ to flatus, 5.9\% to liquid stools, and no incontinence to solid stool [13]; others indicated a significant incontinence rate of $20-67 \%$ [20] and 58\% (103/178) [21] of varying degrees.

The second technique is the loose seton technique developed to avoid cutting the anal sphincter, thereby theoretically reducing incontinence risk. It can be either placed as a long-term indwelling seton [22] or used as a two-staged fistulotomy [23]. Indwelling seton inhibits the pus collection and promotes continuous drainage of the abscess, hence usually placed after the abscess drainage. In some cases, it results in closure of the fistula, generally within six to 12 weeks [24]. In a study by Thornton et al., 28 cases of complex perianal Crohn's fistula had long term indwelling setons, and $92 \%$ cases (26/28) reported an improvement in symptoms at a median follow-up of 13 months [22], while in another study by Fazio et al., fistula closure was reported in $8 \%(16 / 194)$ cases [25]. In a case series led by Kelly et al., 7\% (14/200) had spontaneous resolution of the fistula tract with seton placement alone [1]. The study by Papaconstantinou et al. reported improvement in all 25 cases of mid- or low-level trans-sphincteric fistula in $\mathrm{CD}$, with recurrence six months after seton removal in one patient, and minor incontinence was found in $12 \%(3 / 25)$ [26]. Incontinence rates associated with loose setons have been significantly lower, varied from 5-17\%, compared to cutting setons $[27,28]$. No patient reported a deterioration in fecal continence after seton insertion in a study by Thornton et al. and Kelly et al.

The two-stage seton fistulotomy is more commonly used. Besides continuous drainage, the loose seton placement also incites a fibrotic reaction, which may lead to primary closure or promote migration of the fistula tract superficially, usually within six to eight weeks, after which fistulotomy or fistulectomy can be safely performed. In a study by Kelly et al., 93\% (186/200) underwent two-staged seton fistulotomy, which results in the clearance of fistula in all patients. Only $4 \%$ (eight) described minor urgency, and none reported incontinence at follow-up [1]. Although the study conducted by Galis-Rozen et al., in the Crohn's group, two-staged seton fistulotomy, only 59\% (10) showed significant clinical improvement while $35 \%$ (six) showed no improvement [24]. 


\section{Cureus}

Recently, many surgeons have stopped using the cutting seton technique due to their association with postoperative discomfort and the increased risk of incontinence. Still, many surgeons prefer to use this technique. Incontinence rates associated with loose setons have been significantly lower (5-17\%) compared to cutting setons (20-67\%) [27,28]. It is important to note that most studies conducted before 2000 agree that cutting seton is at a more disadvantageous position than loose setons, but no convincing evidence of superior efficacy [29] or reduced sphincter destruction has been found in later subsequent studies. It is supported by the fact that the studies showed no statistical significance or consisted of a small sample size (low power) to confer strong statistical relevance. In a case series of 59 patients, Drager et al. reported no significant difference in function or healing (92\%) or recurrence rates between the two methods [30]. However, the loose setons' placement remained the preferred choice of surgeons, and many consider it the gold standard for complex fistula [31], even when used as a combination of medical and surgical treatment. In a broader context, loose seton placement, especially as a two-staged seton fistulotomy for a complex fistula, is cost-efficient, well-tolerated, and efficacious (Table 4).

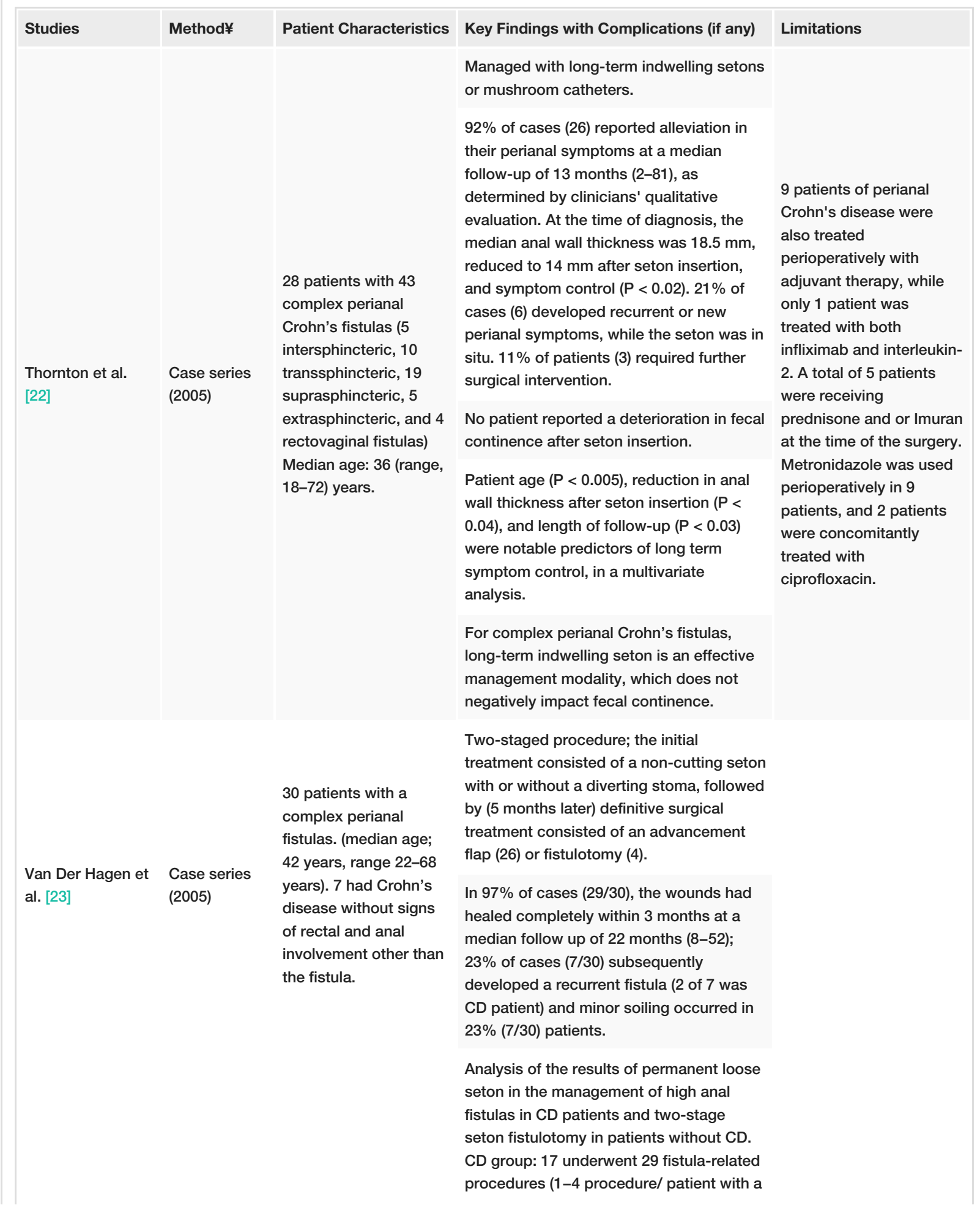




\section{Cureus}

\begin{tabular}{|lll} 
& Case series & $\begin{array}{l}\text { complex fistula out of } \\
\text { which } 60 \text { (42 males) }\end{array}$ \\
{$[24]$} & with & were in the non-CD \\
& comparison & group and $17(12$ \\
& (2009) & males) were in the CD \\
& & group.
\end{tabular}

Chung et al. [32]

Retrospective cohort (2010)

Case series

Kelly et al. [1] (2014) at multicenters

Case series (2016)
77 patients with a complex fistula out of group and 17 (12 group.

51 patients of IBD with anal fistulas were identified, and compared with a control group of 232 patients with non-IBD perianal fistula. The median age was 39 years (range 21-66)

200 patients with anal fistula, out of which 46 patients $(23 \%)$ were of CD. $69.5 \%$ ( $n=139)$ were males, and mean age was 42.6 years. 85 $(42.5 \%)$ were intersphincteric, 71 (35.5\%) were transphincteric, 16 (8 \%) were extrasphincteric, and 12 (6 \%) were suprasphinc- teric. In 16 patients ( $8 \%$ ), the location of the fistula tract was not documented.

51 patients with high perianal fistula Conducted over 12 months median of 1). $59 \%$ (10) showed significant clinical improvement, 35\% (6) showed no improvement, while in $6 \%$ (1), the condition worsened. During the follow-up, $40 \%$ (7) cases had additional procedures.

During a median follow-up of 24 months (6-48), 14/77 (18\%) patients (9 non-CD, 5 CD) experienced long-term morbidity. Among the CD patients, 5 developed a perianal abscess, which required surgical drainage in 4 of which 1 developed fecal incontinence. While among non-CD, 5 required perianal abscess drainage, and another 4 developed minor fecal incontinence.

The approach to complex perianal fistula in CD should be primarily conservative to induce remission and resolution of the fistula. At the same time, in non-CD, it should be surgical. With these tactics, surgery becomes an option when drug therapy fails.

At 12 weeks in the treatment group for the seton drain (40 cases), flap advancement (5 cases), fistula plug ( 4 cases), and fibrin glue ( 2 cases), the postoperative healing rates were $28 \%, 20 \%, 75 \%$, and $0 \%$, respectively. These procedures did not alter continence scores.

Healing rates were not statistically significantly different between the 4 treatment groups. Small sample size and low power to confer strong statistical relevance Disproportionate distribution of patients among groups.

Managed with loose seton placement. $96 \%$ of patients $(187 / 200)$ tolerated the procedure with no complications, while $3 \%(6 / 200)$ had a local reaction secondary to the seton material requiring it to be changed, and $1 \%(2 / 200)$ could not tolerate the presence of seton due to significant perianal discomfort.

All patients had a successful clearance of fistula. 93\% (186/200) had a controlled fistulotomy when there was minimal sphincter involvement, while the remaining $7 \%(14 / 200)$ had spontaneous resolution of the fistula tract with seton placement alone.

At a 6-monthly follow-up, the fistula recurrence rate was noted to be $6 \%(12)$, while only $4 \%$ (8) reported minor urgency, and none reported incontinence at followup.

Managed with cutting seton insertion technique. $90.2 \%$ healing rate (complete cure) by the end of the study, with a recurrence rate of $9.8 \%$. A direct correlation was noticed between the healing time and the distance from the anal verge.

Patients with low perianal fistula were excluded Crohn's disease patient were excluded.
Lack of long-term followup Retrospective

was $15.7 \%$ to flatus, $5.9 \%$ to liquid stools 


\section{Cureus}

Papaconstantinou Case series et al. [26] (2016)

Wasmann et al. [10]
44 of the 126 planned patients with high perianal Crohn's fistulas with a single internal opening were

Randomized randomly assigned controlled trial (2020) of the 126 declined
59 patients of perianal Crohn's fistula were identified. High transsphincteric fistula (44\%), mid or low transsphincteric fistulas (51\%) and rectovaginal fistula (5\%). with no incontinence to solid stools.

Managed with loose seton placement (all cases of high trans-sphincteric fistulas), fistulotomy, or seton placement based on the clinical evaluation (all cases with midor low-level trans-sphincteric fistula).

Out of 59 cases, 29, 1, 25, and 4 underwent fistulotomy, fistulotomy with a proximal diverting colostomy, seton placement, and seton placement with a proximal diverting colostomy, respectively.

Seton placement is more appropriate and is the only option for more high-lying or complicated fistulae. Fistulotomy could achieve good outcomes in wound healing and incontinence in strictly selected patients with CD suffering from low-lying trans-sphincteric fistulae.

The mean follow-up duration was $1.6 \pm 1.1$ years. One patient in the seton placement group experienced recurrence six months after seton removal, and one patient in the fistulotomy group failed to achieve wound healing. Minor incontinence was noticed in six patients treated with fistulotomy and in three patients treated with seton placement; however, this difference was not significant (chi-square $=1.723, p=$ 0.273).

Before randomization, all patients underwent seton insertion [vessel loop] under general anesthesia in a daycare setting and received a 2-week antibiotic course. Furthermore, 6-mercaptopurine [6-MP] was added. Random assignment to the following groups, with follow up for 1.5 years: Chronic seton drainage for 1 year (15 cases); Anti-TNF therapy for 1 year (15 cases); Surgical closure after 2 months under a short course anti-TNF (14 cases). In the PISA prospective registry cohort, 20 patients chose chronic seton drainage, 21 anti-TNF treatment, and 9 surgical closure after anti-TNF induction.

The primary outcome was the cumulative number of patients with fistula-related reintervention[s] at 1.5 years.

In the randomized group, seton treatment between 2013-2017.50 was associated with the highest rerandomization due to treatment preference hence were included in a parallel prospective PISA registry cohort. intervention rate $[10 / 15$, versus $6 / 15$ antiTNF and $3 / 14$ surgical closure patients, $p$ $=0.02]$. No substantial differences in PDAI and quality of life between the three treatment groups were observed.

Interestingly, in the PISA prospective registry cohort, the re-intervention rate was similar between the groups $(42 \%$ [ 8 cases], $48 \%$ [ 9 cases], and $44 \%$ [ 2 cases] in the chronic seton, anti-TNF, and the
All patients included in this study were administered ciprofloxacin $400 \mathrm{mg} \mathrm{BD}$ and metronidazole 500 mg TDS, with the first dose being given preoperatively and continued postoperatively for at least 7 days.
The study was stopped by the data safety monitoring board because of futility. 


\section{Cureus}

surgical closure after anti-TNF groups; $p=$ $0.78)$. It is worth noticing that the inferiority of chronic seton treatment was not observed for any outcome measure.

Based on the results, the authors recommended that chronic seton treatment should not be recommended as the sole treatment for perianal Crohn's fistulas.

TABLE 4: Clinical studies on the management of perianal Crohn's fistula primarily by the Seton's placement or the combination of therapies

¥ Published date; CD (Crohn’s Disease); non-CD (Non-Crohn’s Disease); PDAI (Perianal Disease Activity Index), TNF (tumor necrosis factor)

Biologicals

The pathogenesis (Figure 3) of Crohn's disease involves Th1 and Th17 hypersensitivity due to an unknown antigen (possibly enteric floral antigens) within the intestinal mucosa. Increased production of TGF- $\beta$ and IL-6 is responsible for the commitment of naive Th cells (Th0 cells) to Th17 cells, while IL-12 is required for differentiation of a Th0 cell into a Th1 cell. The production of IL-21 and IL-23 is responsible for the maintenance and expansion of the Th17 cells, while the local production of TNF- $\alpha$ mediates and propagates the inflammation [14]. In the inflammatory infiltrate, IL-12, TNF, and IL-13 induce epithelial-tomesenchymal transition and upregulation of matrix metalloproteinases, leading to tissue remodeling and fistula formation [15]. Therefore any pharmacological agent interrupting this pathway will theoretically resolve the inflammation and the progression of the disease. The antagonist to TNF- $\alpha$ has been approved for the management of Crohn's disease and its complications.

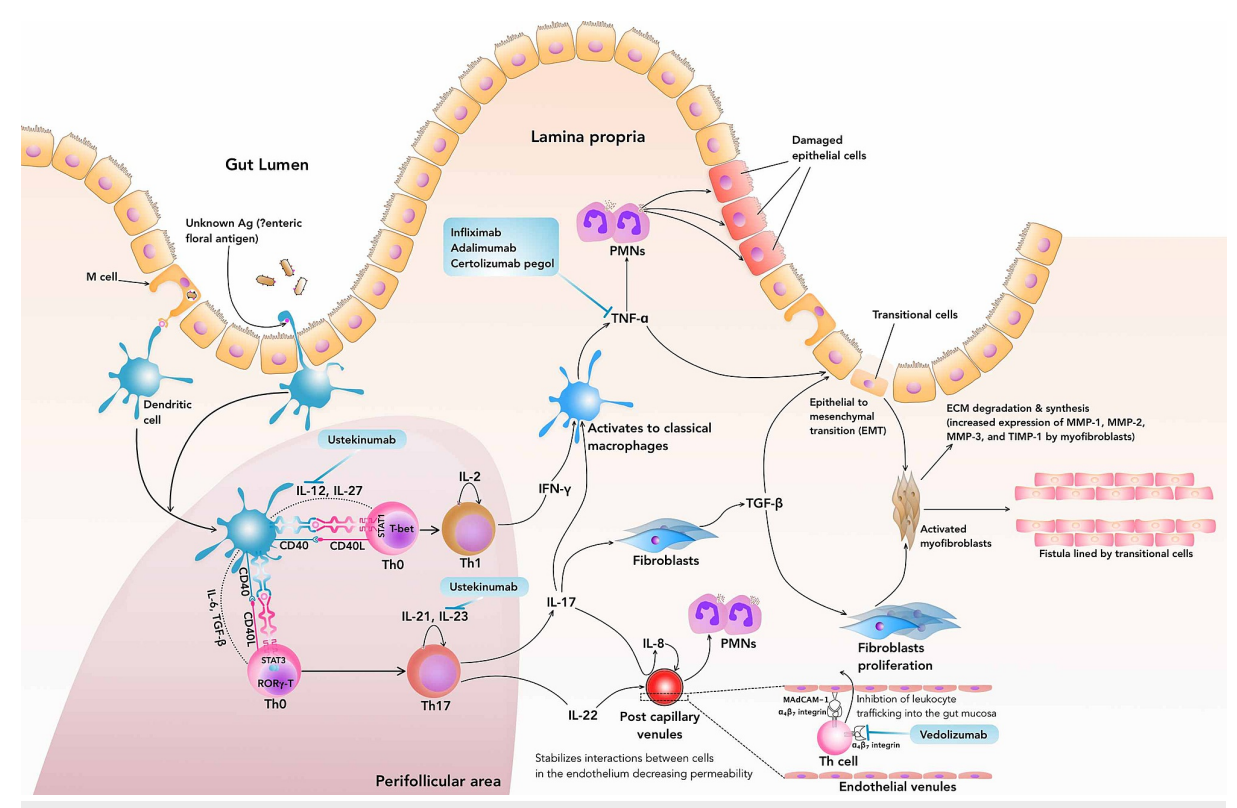

FIGURE 3: Immunopathogenesis of Crohn's Disease \& Fistula Formation and the Development of Novel Target Immune therapies (Biologicals) affecting the Pathway

Th: T Helper cells; IL: Interleukin; TNF: Tumor Necrosis Factor; IFN: Interferon; TGF: Transforming growth factor; CD: Cluster of Differentiation; Ag: Antigen; MMPs: Matrix Metalloproteinases; TIMPs: Tissue Inhibitors of Matrix Metalloproteinases; MAdCAM: Mucosal Addressin Cell Adhesion Molecule; PMNs:

Polymorphonuclear leukocytes; STAT: Signal transducer and activator of transcription (a transcription factor); T-bet: (T-box expressed in T cells, a T-box transcription factor); RORy: RAR-related orphan receptor gamma (a member of the nuclear receptor family of transcription factors).

In a study conducted by Present et al. on patients with perianal Crohn's fistula, infliximab IV at $5 \mathrm{mg} / \mathrm{kg}$ resulted in $\mathrm{a} \geqslant 50 \%$ reduction in the number of draining fistula in $68 \%$ of the patients as compared to the 
placebo ( $\mathrm{p}=0.02$ ), while $55 \%$ had the fistula closure [33]. In another study by Farrell et al., $70 \%$ (23/33) of patients with fistulous disease experienced $>50 \%$ reduction in their Perianal Disease Activity Index (PDAI) at two weeks with $5 \mathrm{mg} / \mathrm{kg}$ infusion of infliximab [34]. Similarly, in a prospective cohort study by Luna-Chadid et al., after the third infusion of infliximab $(5 \mathrm{mg} / \mathrm{kg}$ ), the response was partial ( $\geqslant 50 \%$ from baseline) in $26 \%$ $(27 / 105)$ and complete (full closure) in $57 \%$ (60/105), i.e., $82 \%$ (87/105) were responders with infliximab four weeks post-infusion of the last dose [35]. A randomized controlled trial (RCT) by Sands et al. found the response rate to be $43 \%$ (130/305) in perianal Crohn's fistulous patients who received three infusions of Infliximab at 0 , two, and six weeks and the median time for the loss of response after receiving three infusions of infliximab was 14 weeks [36]. To conclude that infliximab does have a statistically significant effect on the healing rate as compared to placebo for the perianal Crohn's fistula, but it also requires a prolonged maintenance dose after induction therapy to maintain the remission. A study by Yarur et al. [37] also proves an incremental gain in fistula healing with higher infliximab levels. The area under the curve (AUC) for the association between fistula healing and infliximab levels was $0.82(\mathrm{p}<0.0001)$, while the AUC for the association of infliximab levels and fistula closure was $0.69(\mathrm{p}=0.014)$. The patients who did not show any improvement or lower infliximab levels in serum were having anti-infliximab antibodies and had a lower chance of achieving fistula healing (OR: 0.04 [95\% CI: 0.005-0.3], p < 0.001).

Adalimumab (ADA) is a fully human anti-TNF IgG1 monoclonal antibody that has also been shown to induce and maintain clinical response in active $\mathrm{CD}$ not controlled by corticosteroids, immunosuppressants, or both, but the results of its overall effectiveness are questionable, while the effect on fistula improvement has not been proven so far. In an RCT (CLASSIC-I: Clinical assessment of Adalimumab Safety and efficacy Studied as Induction therapy in Crohn's disease) conducted by the Hanauer et al. [38] on perianal Crohn's fistula patients, the rates of remission for the Crohn's disease at week four in the adalimumab $40 \mathrm{mg} / 20 \mathrm{mg}$, $80 \mathrm{mg} / 40 \mathrm{mg}$, and $160 \mathrm{mg} / 80 \mathrm{mg}$ groups were $18 \%(\mathrm{p}=0.36), 24 \%(\mathrm{p}=0.06)$, and $36 \%(\mathrm{p}=0.001)$, respectively, and $12 \%$ in the placebo group. While the rates of fistula improvement at week four in the adalimumab $40 \mathrm{mg} / 20 \mathrm{mg}, 80 \mathrm{mg} / 40 \mathrm{mg}$, and $160 \mathrm{mg} / 80 \mathrm{mg}$ groups were $3 / 4$ (75\%), 2/10 (20\%), and $1 / 12$ (8\%) respectively, and $2 / 6(33 \%)$ in the placebo group, and the rates of fistula remission at week four in the adalimumab $40 \mathrm{mg} / 20 \mathrm{mg}$, $80 \mathrm{mg} / 40 \mathrm{mg}$, and $160 \mathrm{mg} / 80 \mathrm{mg}$ groups were $3 / 4$ (75\%), 0/10 (0\%), and 0/12 (0\%) respectively, and $1 / 6(17 \%)$ in the placebo group. Therefore adalimumab was not found to be superior to placebo in the management of the perianal fistula treatment. However, with a minimal beneficial effect on the rates of remission in moderate to severe Crohn's disease compared to placebo (note only the highest dose group at week four achieved statistical significance [ $p=0.001]$ as compared to placebo). The CLASSIC-II trial (RCT) by Sandborn et al. [39] was a continuation of the CLASSIC-I trial to observe adalimumab's effect on the maintenance of remission. Group I consisted of 55 patients in remission were re-randomized and received adalimumab 40mg every other week (19 patients; Group 1a), 40mg weekly (18 patients; Group 1b), or placebo (18 patients; Group 1c) for 56 weeks, while the Group II consisted of the patients who were not in remission received open-label adalimumab 40mg at weeks 0 (week four of CLASSIC I) and two. There was a statistically significant difference in the remission rate in Group 1a $(15 / 19,79 \%), 1 \mathrm{~b}(15 / 18,83 \%)$ versus placebo $(8 / 18,44 \%)$ at week 56 . Unfortunately, no direct data for fistula improvement or remission was presented in this study. In another RCT by Sandborn et al., [40] the rates of fistula improvement and remission at week four were $15 \%$ (3/20) of patients in the adalimumab group versus $20 \%(5 / 25)$ of patients in the placebo group for improvement and 5\% (1/20) versus $8 \%(2 / 25)$, respectively, for remission. Although the sample was of small size, nevertheless, it explains that the use of the adalimumab for the improvement or remission of perianal Crohn's fistula is futile. In a large scale RCT (CHARM: Crohn's Trial of the Fully Human Antibody Adalimumab for Remission Maintenance; phase III of CLASSIC-I trial) by Colombel et al. [41], complete fistula closure (closure of all fistulas that were draining at screening and baseline visits) were achieved in the randomized population at both week 26 and week 56 (30\% [21/70] and 13\% [6/47] for combined adalimumab groups and placebo group, respectively, at week $26(\mathrm{p}=0.043)$ and $33 \%[23 / 70]$ and $13 \%$ [6/47] for combined adalimumab groups and placebo group, respectively, at week $56(p=0.016))$. Of patients with complete fistula closure at week $26,100 \%$ continued to have complete fistula closure at week 56 [41]. The major limitation of this study is that the many patients receiving placebo ceased treatment because of an adverse event (13.4\%) than those receiving adalimumab, which might have increased the contrast between the treatment and placebo groups.

Certolizumab pegol is a pegylated humanized Fab' fragment that binds TNF- $\alpha$. In an RCT conducted by Sandborn et al., 662 patients with moderate-severe Crohn's disease were assigned randomly to receive either $400 \mathrm{mg}$ of certolizumab pegol or placebo subcutaneously at weeks 0 , two, and four and then every four weeks. In the overall population, at week six, induction response rates based on Crohn's Disease Activity Index (CDAI) were $35 \%$ in the certolizumab group and $27 \%$ in the placebo group $(p=0.02)$; at both weeks six and 26 , the response rates were $23 \%$ and $16 \%$, respectively $(p=0.02)$. Through week $26,30 \%(14 / 46)$ of patients in the certolizumab group had fistula closure compared to $31 \%(19 / 61)$ of patients in the placebo group [42]. So as per the study, certolizumab does have a modest effect in response rates in patients with moderate to severe Crohn's disease, but the use of the certolizumab pegol for the fistula closure in the case of Crohn's does not show any effect in contrast to the placebo (statistically significant finding). The major limitation of the trial was that many patients were also receiving concurrent therapy, so the statistically significant effect of certolizumab therapy presented in the study can not be conclusively established whether it was the effect of the certolizumab or the concurrent therapy or the combination of the therapy. However, the concurrent treatment was proportionately divided into the placebo and the certolizumab group. Schreiber et al. [43] performed a similar RCT; 668 adults with moderate-severe Crohn's disease 
entered the induction phase. Fourteen percent (58/425; 28 in the certolizumab group and 30 in the placebo group) of patients who responded to induction therapy with certolizumab pegol had draining fistulas at baseline. In the certolizumab group, 54\% (15/28) had closure of the fistula (defined as the absence of drainage on gentle compression at any two consecutive visits three weeks apart), compared with 43\% (13/30) in the placebo group. Again no statistical significance was noted for the fistula closure with certolizumab pegol therapy as compared to the placebo. However, another subsequent RCT by the same author included 108 adults with draining Crohn's fistula, out of which nonresponders (50/108) at week six to open-label certolizumab therapy were excluded. The responders (the majority 55/58 had perianal fistula) were then randomized to certolizumab pegol 400mg $(n=28)$ or placebo $(n=30)$ every four weeks. It was found that at week $26,36 \%$ of patients in the certolizumab pegol group had $100 \%$ fistula closure compared with $17 \%$ of patients receiving placebo $(\mathrm{p}=0.038)$. The major limitations of the results are the exclusion of the nonresponders and the small sample size to confer any statistical significance. The study also concluded that the protocol-defined fistula closure $(\geqslant 50 \%$ closure at two consecutive post-baseline visits $\geqslant$ three weeks apart) was not statistically significant ( $\mathrm{p}=0.069)$, with $54 \%$ and $43 \%$ of patients treated with certolizumab pegol and placebo achieving this endpoint, respectively [44].

Vedolizumab is a monoclonal antibody directed against the $\alpha_{4} \beta_{7}$ integrin on the T cells, inhibiting the T cells' transmigration, limiting the trafficking into the GI mucosa. In an RCT (NCT00783692 trial) conducted by Sandborn et al. [45], 368 patients (group 1) were randomly assigned to receive either IV vedolizumab (300mg; Group 1a; 220 cases) or placebo (Group 1b; 148 cases) at weeks 0 and two, while 747 patients (Group 2) received the open-label vedolizumab at weeks 0 and two. At week six, 461 showed a response to vedolizumab (vedolizumab responders), who were then randomly assigned to receive either IV vedolizumab (300mg) every four weeks (Group 2a; 154 cases) or every eight weeks (Group 2b; 154 cases) or placebo (Group $2 c ; 153$ cases) until week 52 . At the end of the induction phase, at six weeks, $14.5 \%(32 / 220)$ in Group 1a and $6.8 \%(10 / 148)$ in Group $1 b$ had a clinical remission, i.e., CDAI of $\leqslant 150(p=0.02)$. While in Group 2, $17.7 \%$ $(132 / 747)$ had a clinical remission. At the end of the maintenance phase, at week $52,36.4 \%(56 / 154)$ in Group 2a and 39\% (60/154) in Group 2b achieved clinical remission, as compared to 21.6\% (33/153) in Group 2c (p < 0.001 and $\mathrm{p}=0.004$ for the comparison of the two vedolizumab groups, respectively, with placebo). While at week 52 , the fistula closure rates in Group $2 \mathrm{a}$ and $2 \mathrm{~b}$ were $22.7 \%(5 / 22)$ and $41.2 \%(7 / 17)$ compared to $11.1 \%$ $(2 / 18)$ in Group 2c $(p=0.32$ and $p=0.03$, respectively). Although with a modest effect on systemic disease, vedolizumab-treated active Crohn's disease patients were more likely to be in remission than placebo during induction and maintenance. While vedolizumab's effect on fistula closure rate in the maintenance phase of vedolizumab responders did not reach statistical significance in Group 2a, but with a minimal statistically significant impact on fistula closure rate in Group $2 \mathrm{~b}$ compared to placebo. Vedolizumab, compared to placebo, was associated with a higher rate of serious adverse events (24.4\% vs. $15.3 \%)$, infections (44.1\% vs. $40.2 \%$ ), and serious infections (5.5\% vs. $3.0 \%$ ).

In a retrospective analysis of the NCT00783692 trial (2018) by Feagan et al. [46], at the end of the induction phase at week six, 12\% (57/461) of vedolizumab responders (Group 2) had $\geqslant$ one active draining fistula, which was randomly assigned to receive either IV vedolizumab (300mg) every four weeks (22 cases) or every eight weeks (17 cases) or placebo (18 cases) until week 52. Note, 79\% (45/57) had perianal draining Crohn's fistula, of which 32 were allotted in vedolizumab-treated group, while 13 were in the placebo group. By week $14,28 \%(11 / 39)$ of vedolizumab-treated patients compared with $11 \%(2 / 18)$ of placebo-treated patients (absolute risk reduction [ARR] 95\% confidence interval [CI], -11.4 to 43.9) achieved fistula closure. Respective rates at week 52 were $31 \%$ (12/39) and 11\% (2/18) (ARR: 19.7\%; 95\% CI, -8.9 to 46.2). Similar results were observed in the patients with only perianal fistulae: $34 \%(11 / 32)$ in the vedolizumab-treated patients compared to $15 \%(2 / 13)$ in the placebo group. Respective values at week 52 were $31 \%(10 / 32)$ in the vedolizumab-treated while $11 \%$ (2/13) in the placebo group [ARR: $19.7 \%$; $95 \%$ CI, -8.9 to 46.2 ]. There are several key points worth noting about this retrospective analysis; first, the response rate to vedolizumab in the NCT00783692 trial at the end of the induction phase was $47.67 \%(461 /(220+747))(\mathrm{CDAI} \leqslant 150)$. Only 45 had active perianal draining Crohn's fistula. With the vedolizumab responders, the fistula closure rate was significantly lower (31\%) at the end of week 52 in the maintenance phase of the responders. The confidence interval of the absolute risk reduction at week 14 crosses 0 , indicating not statistically significant, although the p-value of the ARR was not calculated. Albeit the sample's small size to confer a strong statistical relevance, the modest achievement in fistula closure and its rate was worthwhile. But if we include the vedolizumab non-responders in our calculation, the fistula closure rate at week 52 becomes $12 /(39+85)=$ $9.67 \%$ ( $\approx 10 \%$ ). It would decrease further if we include only Crohn's fistula. The question arises would it be worthwhile to supplement the patient of perianal Crohn's fistula with vedolizumab considering the low response rate $(<9.67 \%)$ and severe adverse reaction $(24.4 \%)$.

To sum up, among biologicals, infliximab is the only therapy that has a statistically significant effect on the healing rate of perianal Crohn's fistula compared to placebo, but it also requires a prolonged maintenance dose after induction therapy to maintain the remission. The efficacy of adalimumab and certolizumab pegol for the healing or closure of perianal fistula closure has not been established in the study since the statistical significance is lacking compared to placebo. The efficacy of vedolizumab, albeit significantly lower but statistically significant for the remission of the perianal Crohn's fistula, is counterbalanced by the severe adverse reaction associated with its use. Therefore the use of either therapy for the sole purpose of fistula healing or closure in case of Crohn's disease would be futile. 


\section{Cureus}

Setons and Biologicals

The reported re-intervention rates in the case of perianal Crohn's fistula with seton drainage were 10-20\% [28] compared with anti-TNF or surgical closure $30-50 \%$. This is in contrast with an RCT (PISA trial) by Wasmann et al. where 44/126 patients with high perianal Crohn's fistulas were randomly assigned between 2013-2017 into three groups: chronic seton drainage for one year (15 assigned; Group 1a); anti-TNF therapy for one year (15 assigned; Group 1b); and surgical closure after two months under a short course anti-TNF (14 assigned; Group 1c). Fifty of 126 declined randomization due to treatment preference hence were included in a parallel prospective PISA registry cohort and chose one of the three options (20 patients [Group 2a], 21 patients [Group 2b], and nine patients [Group 2c]) [10].

The primary outcome measure was the fistula-related re-intervention rate at 1.5 years. It was determined that the seton treatment was associated with the highest re-intervention rate (10/15, versus $6 / 15$ anti-TNF and $3 / 14$ surgical closure patients, $p=0.02$ ), while the re-intervention rates in the PISA cohort were $42 \%$, $48 \%$, and $44 \%$. No substantial differences in PDAI and quality of life between the three treatment groups were observed. It was found that the seton treatment was associated with the highest re-intervention rate $(10 / 15$, versus $6 / 15$ anti-TNF and $3 / 14$ surgical closure patients, $p=0.02)$. It is worth mentioning that chronic seton treatment's inferiority was not observed for any outcome measure in the PISA cohort [10]. The limitation with this study is that the study included a small sample size in the randomized group (44 cases), hence the low power to confer strong statistical relevance, seven patients in Group 1a also received the antiTNF therapy, four patients in Group $1 \mathrm{~b}$ also received the additional seton. The sample size needed to detect the statistically significant difference in re-intervention rate with two-sided chi-squared testing equals 42 patients per group, or 126 patients overall (alpha 0.05 , power $80 \%$ and $5 \%$ dropout rate), while the patients in each group did not full-fill the criteria [47] (as suggested by the authors in their first publication). This intermingling of the therapy within the group on a small sample blurred the picture of the re-intervention rate, hence unable to draw firm conclusions (Table 5).

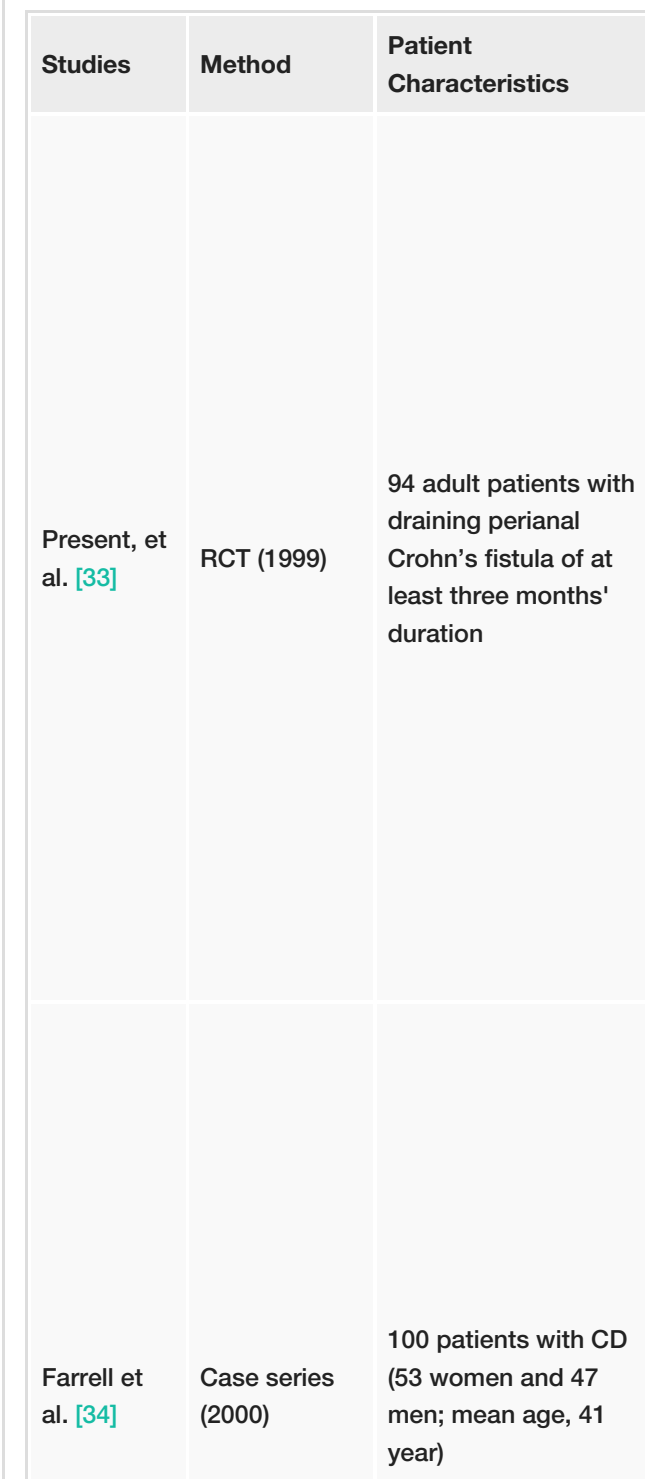

Key Findings with Complications (if any)

Limitations
All patients were randomly assigned to receive IV infusions at weeks 0,2 , and 6 to one of the three groups: Group 1 (placebo; 31 patients), Group 2 (5 mg/kg of Infliximab; 31 patients), and Group 3 (10 $\mathrm{mg} / \mathrm{kg}$ of Infliximab; 32 patients)

The primary endpoint was a reduction of $\geq 50 \%$ from baseline in the number of draining fistulas observed at $\geq$ 2 consecutive study visits. The secondary endpoint was the closure of all fistulas.

$68 \%(21 / 31)$ of Group 2 and $56 \%(18 / 32)$ of Group 3 achieved the primary endpoint, as compared with $26 \%$ (8/31) of Group 1 ( $P=0.002$ and $P=0.02$, respectively). While $55 \%$ (17/31) of Group 2 and 38\% (12/32) of Group 3 had closure of all fistulas, as compared with $13 \%$ (4/31) of Group 1 ( $P=0.001$ and $P=0.04$, respectively). The median length of time during which the fistulas remained closed was three months.

$>60 \%$ of patients in all the groups had adverse events, most commonly headache, abscess, upper respiratory tract infection, and fatigue, especially in patients treated with Infliximab.

All patients were divided into three groups, namely active disease (57 patients), perianal fistulous disease (33 patients), and steroid dependency (10 patients) group, based on the clinical status and received IV infusions $(5 \mathrm{mg} / \mathrm{kg})$ at weeks 0,2 , and 6 , with a total of 233 infusions.

All patients in the perianal fistulous disease group had 50 draining fistulas (19 had one fistula, 11 had two fistulas, and 3 had three fistulas).

$70 \%(23 / 33)$ cases in the fistulous disease group experienced $>50 \%$ reduction in their PDAl at two weeks; 


\section{Cureus}

$\begin{array}{lll}\text { Sands et } & \text { RCT (2004) } & \begin{array}{l}\text { draining perianal } \\ \text { al. [36] }\end{array} \\ & \begin{array}{l}\text { Crohn's fistula of at } \\ \text { least three months' } \\ \text { duration }\end{array}\end{array}$

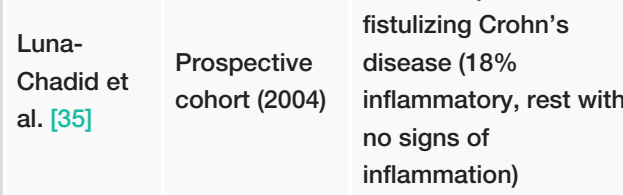

Yarur et al. Cross-

[37] sectional (2017) the mean duration of response was 10.9 weeks. $78 \%$ $(18 / 23)$ of this group maintained this reduction at 18 weeks.

$6.9 \%$ of infusions $(16 / 233)$ resulted in adverse reactions, including 14 experienced infectious adverse events, 13 of whom were on concurrent steroids, 1 experienced an anaphylactic shock.

After receiving $5 \mathrm{mg}$ of infliximab/kg IV (induction) on weeks 0,2 , and 6 , all patients were randomly assigned based on the response status at week 14 into two groups (responders [195 patients] and non-responders [87 patients]) to receive either a placebo or $5 \mathrm{mg}$ of Infliximab/kg (maintenance) every 8 weeks and to be followed to 54 weeks.

Responders demonstrated rapid onset of response with an increase in response rate after every infusion (induction).

Before randomization, a complete response was observed in 31\% (95/306), 43\% (130/305; 1 patient discontinued treatment), and $48 \%(147 / 305)$ at weeks 2 , 6 , and 14 , respectively.

After randomization, the median time to the loss of response, hence a need for a change in the treatment of CD (the primary analysis) was 14 weeks in the placebo maintenance group, compared to $>40$ weeks in the Infliximab maintenance group $(p<0.001)$ after randomization.

All patients received $5 \mathrm{mg}$ of infliximab/kg IV (induction) on weeks 0,2 , and 6 . Partial response was defined as a reduction of $\geq 50 \%$ from the base-line in the number of draining fistulae, while a complete response was defined as the closure of all fistulae.

$26 \%(27 / 105)$ and $57 \%(60 / 105)$ demonstrated a partial and complete response (total $82 \%$ responders),

respectively, four weeks post-infusion of the last dose of Infliximab.

Based on the fistula location, the response rates (partial/complete\%) were: enterocutaneous (25/68\%), perianal $(35 / 60 \%)$, rectovaginal $(36 / 64 \%)$, and enterovesical (20/40\%).

In the multivariate analysis, none of the studied variables (including concomitant immunosuppressive therapy) correlated with Infliximab's efficacy.

The incidence of adverse effects (21\%) depending on the dose of Infliximab was: first dose $(5.6 \%)$, second (7.4\%), and third (11.1\%).

Managed with infliximab for at least 24 weeks.

Significantly higher median serum infliximab levels were found in patients exhibiting healing of the fistula compared to those with active fistulas [15.8 vs. 4.4 $\mu \mathrm{g} / \mathrm{mL}$, respectively $(P<0.0001)]$.

The Infliximab levels were directly correlated with the fistula healing rate. The area under the curve (AUC) for the association between fistula healing and infliximab levels was $0.82(P<0.0001)$, while the AUC for the association of infliximab levels and fistula closure was $0.69(P=0.014)$. Achieving infliximab levels $\geq 10.1 \mu \mathrm{g} / \mathrm{mL}$
The percentages of patients receiving concurrent therapy with other drugs were: azathioprine/6mercaptopurine (68\%), corticosteroids (55\%), 5aminosalicylates (75\%), metronidazole (67\%), and ciprofloxacin (32\%). 


\section{Cureus}

\section{Hanauer et RCT (2006): trial}

\section{RCT (2007):}

Sandborn et al. [39]
299 patients with moderate to severe $C D$ naive to anti-TNF therapy, with $11 \%$ $(32 / 299)$ had draining enterocutaneous or perianal fistulas and were unevenly distributed across the treatment groups. in patients with CD and perianal fistulas may improve outcomes as part of a treat-to-target strategy.

Patients with anti-infliximab antibodies had a lower chance of achieving fistula healing (OR: 0.04 [95\% Cl: 0.005-0.3], P $<0.001$ ).

All patients were randomized to receive $S Q$ injections of Adalimumab $40 \rightarrow 20 \mathrm{mg}, 80 \rightarrow 40 \mathrm{mg}$, or $160 \rightarrow 80 \mathrm{mg}$ or placebo $\rightarrow$ placebo at weeks 0 and 2 , respectively.

The primary endpoint was the determination of a significant difference in remission rates (defined as a CDAl score $<150$ points) at week 4 among the four groups. At weeks 4 , the rates of remission of the CD in the adalimumab $40 \rightarrow 20 \mathrm{mg}, 80 \rightarrow 40 \mathrm{mg}$, and $160 \rightarrow 80$ mg groups were $18 \%(P=.36), 24 \%(P=.06)$, and $36 \%$ $(P=.001)$, respectively, while $12 \%$ in the placebo group. All four groups experienced adverse effects at similar frequencies except injection site reactions, which were more common in adalimumab-treated patients.

At week 4, the rates of fistula improvement in the adalimumab $40 \rightarrow 20 \mathrm{mg}, 80 \rightarrow 40 \mathrm{mg}$, and $160 \rightarrow 80 \mathrm{mg}$ groups were $75 \%(3 / 4), 20 \%(2 / 10)$, and $8 \%(1 / 12)$ respectively, and $33 \%(2 / 6)$ in the placebo group. While the rates of fistula remission at weeks 4 in the adalimumab $40 \rightarrow 20 \mathrm{mg}, 80 \rightarrow 40 \mathrm{mg}$, and $160 \rightarrow 80 \mathrm{mg}$ groups were $7 \% \%(3 / 4), 0 \%(0 / 10)$, and $0 \%(0 / 12)$ respectively, and $17 \%(1 / 6)$ in the placebo group. Therefore, the rates of fistula improvement and remission for the adalimumab-treated patients and those receiving placebo were not significantly different.

Adalimumab was not found to be superior to placebo in the management of the perianal fistula treatment..

All received open-label Adalimumab $40 \mathrm{mg}$ at weeks 0 (week 4 of CLASSIC I trial) and 2

55 patients in remission (Group 1) at both weeks 0 and 4 were re-randomized to adalimumab $40 \mathrm{mg}$ every other week (19 patients; Group 1a), 40 mg weekly (18 patients; Group 1b), or placebo (18 patients; Group 1c) for 56 weeks. The primary endpoint was the maintenance of remission (CDAI <150) in randomized patients through week 56.

204 patients (Group 2) who were not in remission were ineligible for randomization hence starts receiving at week 4 , open-label adalimumab $40 \mathrm{mg}$ every other week.

The perianal fistula was present in only $9 \%(5 / 55 ; 3$ in group 1c and 2 in group 1a) in group 1 while $15 \%$ $(30 / 204)$ in group 2.

In group 1 , at week 56 , there was a significant difference in the remission rates between the Group 1a $(79 \%$ [15/19]), Group 1b (83\% [15/18]), and the Group 1c (placebo; 44\% [8/18]) ( $p<0.05$ for each adalimumab group v placebo).

In group 2, 64\% (131/204) completed 56 weeks of treatment, 71 remained on their initial regimens, while 60 had their dosages increased to $40 \mathrm{mg}$ weekly before week $56.46 \%(93 / 204)$ were in remission at week 56.

In patients with moderate to severe Crohn's disease naive to anti-TNF treatment, Adalimumab induced and
Disproportionate distribution of patients among groups.

No control group in the group 2. No direct data for fistula improvement or remission was presented in the study. 


\section{Cureus}

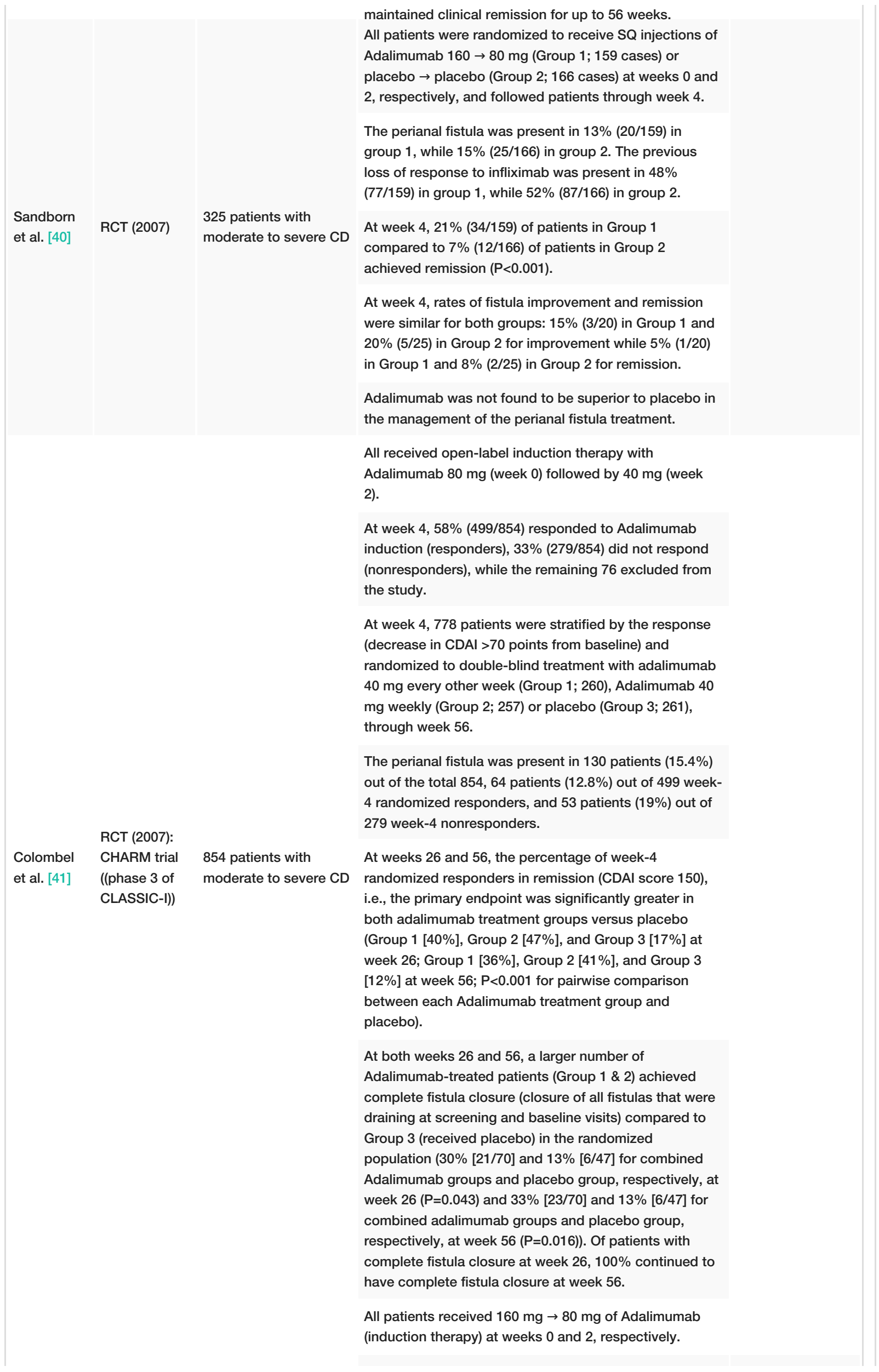




\section{Cureus}

Fortea-

Ormaechea

et al. [48]

Retrospective cohort (2011)

\section{Lichtiger et al. [49] \\ 673 patients with moderate to severe Crohn's disease}

Sandborn et al. [42]
174 adult patients with Crohn's disease. 87 (50\%) had developed perianal fistulizing disease, and among them 53 (30.5\%) had active draining fistulas $59 \%$ (102) of patients received Infliximab therapy in the past, of which 43 (35\%) discontunued due to loss of response.
The maintenance therapy included $40 \mathrm{mg}$ of

Adalimumab every 2 weeks or weekly, depending on the increment in the dose required in case of loss of response to Adalimumab during follow up. So, the dose was escalated in $32.8 \%(57 / 174)$ of patients, and the median time to dose increment was 33 weeks (range 2120).

The authors distinguished the luminal versus perianal fistulizing disease in evaluating the effectiveness of ADA. The complete response rate at 1 month, 6 months, and at the end of follow-up were $63.4 \%, 70.4 \%$, and $63.3 \%$, respectively, in luminal disease, while in the perianal fistulizing disease, these were $49 \%, 50 \%$, and $41.5 \%$, respectively.

No significant difference was noted by the authors in the effectiveness between those who received Adalimumab as first-line treatment and those who had previously received infliximab (50 and $56.3 \%$ of complete response at the end of follow up in luminal disease, $p=0.829$; and 64 and $33.3 \%$ in perianal fistulizing disease, $p=0.164$ ).

After an $\geq 8$-week infliximab washout, all patients with moderate-to-severe $C D$ received open-label adalimumab as induction $(160 \rightarrow 80 \mathrm{mg}$ at weeks 0 and 2 respectively) and maintenance ( $40 \mathrm{mg}$ every other week) therapies. After 8 weeks of treatment, patients with flareups or nonresponders could receive weekly treatment.

$17 \%$ were infliximab primary nonresponders, and $83 \%$ were initial responders. $3 \%$ of patients had severe infections (mainly abscesses).

Complete fistula healing was achieved in $39 \%$ (34/88) patients with baseline fistulas. Improvements in quality of life and work productivity were sustained from week 4 to week 24 for all patients, as well as the subgroup of primary nonresponders.

After stratification according to CRP levels, all patients were randomly assigned to receive either $400 \mathrm{mg}$ of certolizumab pegol or placebo SQ at weeks 0,2 , and 4 and then every 4 weeks.

The primary endpoints were the induction of response at week 6 and response at weeks 6 and 26 .

Among patients with a baseline CRP level of at least 10 $\mathrm{mg} / \mathrm{L}, 37 \%$ of patients in the certolizumab group responded at week 6 compared to $26 \%$ in the placebo group $(P=0.04)$. At both weeks 6 and 26 , the corresponding values were $22 \%$ and $12 \%$, respectively $(\mathrm{P}=0.05)$. While in the overall population, response rates at week 6 were $35 \%$ in the certolizumab group and $27 \%$ in the placebo group ( $\mathrm{P}=0.02)$; at both weeks 6 and 26 , the response rates were $23 \%$ and $16 \%$, respectively $(P=0.02)$.

At weeks 6 and 26, remission rates in the two groups did not differ significantly $(P=0.17)$.

Through week 26, 30\% (14/46) of patients in the certolizumab group had fistula closure compared to $31 \%(19 / 61)$ of patients in the placebo group.

$10 \%$ of patients in the Certolizumab group and $7 \%$ in the placebo group reported severe adverse events, while serious infections were noticed in $2 \%$ and $<1 \%$, 


\section{Cureus}

\begin{tabular}{|c|c|c|c|c|}
\hline & & & $\begin{array}{l}\text { respectively. Antibodies to the drug and antinuclear } \\
\text { antibodies developed in } 8 \% \text { and } 2 \% \text { of the patients in } \\
\text { the Certolizumab group, respectively. }\end{array}$ & \\
\hline $\begin{array}{l}\text { Schreiber } \\
\text { et al. [43] }\end{array}$ & RCT (2007) & $\begin{array}{l}668 \text { adults with } \\
\text { moderate-to-severe } \\
\text { Crohn's disease } \\
\text { entered the induction } \\
\text { phase }\end{array}$ & 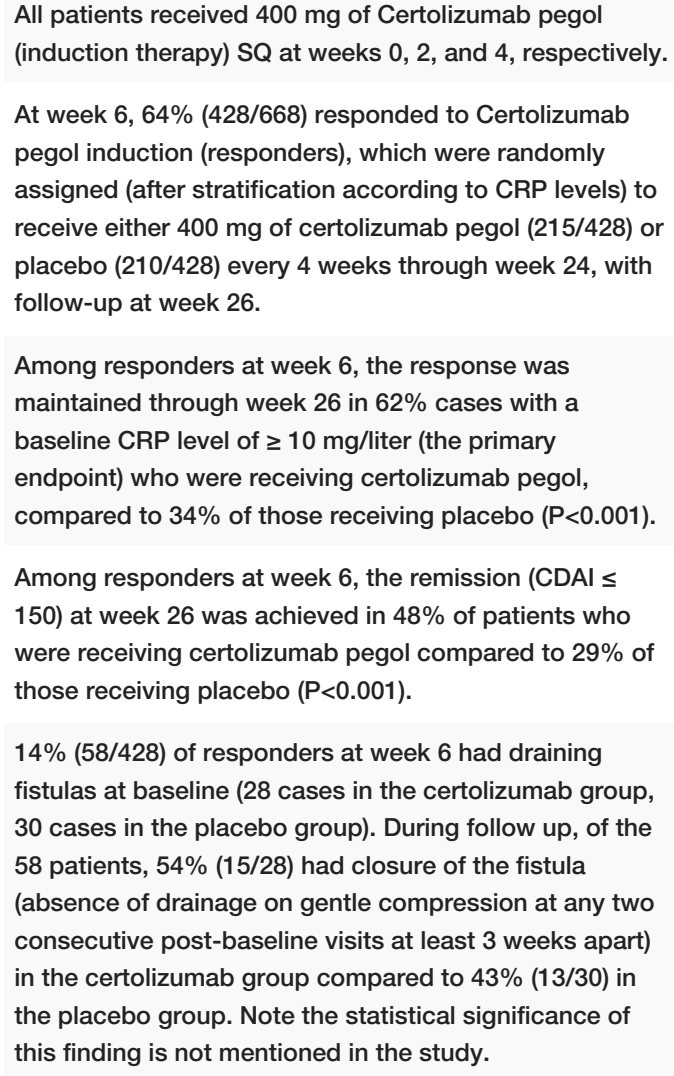 & \\
\hline \multirow[t]{2}{*}{$\begin{array}{l}\text { Schreiber } \\
\text { et al. [44] }\end{array}$} & RCT (2011) & $\begin{array}{l}108 \text { adults with } \\
\text { draining Crohn's fistula }\end{array}$ & $\begin{array}{l}\text { All patients received } 400 \mathrm{mg} \text { of Certolizumab pegol } \\
\text { (open-label induction therapy) SQ at weeks } 0,2 \text {, and } 4 \text {. } \\
\text { The response was defined as a } \geq 100 \text {-point decrease } \\
\text { from baseline in the CDAl. } \\
\text { At week } 6 \text {, nonresponders }(50 / 108) \text { were excluded. While } \\
\text { responders with draining fistulas (58/108) were } \\
\text { randomized to certolizumab pegol } 400 \mathrm{mg}(28 / 58) \text { or } \\
\text { placebo (30/58) every } 4 \text { weeks across weeks } 8-24 \text {. } \\
\text { Assessment of fistula closure was performed throughout } \\
\text { the study, with a final evaluation at week } 26 \text {. }\end{array}$ & $\begin{array}{l}\text { Exclusion of the } \\
\text { nonresponders } \\
\text { and small sample } \\
\text { size to confer any } \\
\text { statistical } \\
\text { significance }\end{array}$ \\
\hline & & & $\begin{array}{l}\text { In the induction phase, } 368 \text { patients (group } 1 \text { ) were } \\
\text { randomly assigned to receive either IV Vedolizumab ( } 300 \\
\text { mg; Group 1a; } 220 \text { cases) or placebo (Group } 1 \text { b; } 148 \\
\text { cases) at weeks } 0 \text { and 2, while } 747 \text { patients (group 2) } \\
\text { received the open-label Vedolizumab at weeks } 0 \text { and } 2 . \\
\text { In the maintenance phase, } 41.34 \% \text { ( } 461 / 1115 \text {; Group 2) } \\
\text { who had a response at week } 6 \text { (Vedolizumab- }\end{array}$ & \\
\hline
\end{tabular}




\section{Cureus}

$\begin{array}{lll} & & \begin{array}{l}1115 \text { adult patients } \\ \text { enrolled with active }\end{array} \\ \text { Sandborn } & \text { RCT (2013): } & \begin{array}{l}\text { Crohn's disease, with } \\ \text { et al. [45] }\end{array} \\ & \begin{array}{l}\text { NCT00783692 } \\ \text { trial }\end{array} & \begin{array}{l}\text { h10 patients had a } \\ \text { history of fistulizing } \\ \text { disease, and 165 had } \\ \text { active draining fistula. }\end{array}\end{array}$

Retrospective

exploratory Vedolizumab

Feagan et analysis of responders (461/1115)

al [46] the of the NCT00783692

NCT00783692 trial

trial (2018) responders) were then randomly assigned to receive either IV Vedolizumab (300 mg) every 4 weeks (Group 2a; 154 cases) or every 8 weeks (Group 2b; 154 cases) or placebo (Group 2c; 153 cases) until week 52.

At the end of the induction phase, at 6 weeks, $14.5 \%$ (32/220) in Group 1a and 6.8\% (10/148) in Group 1b had a clinical remission, i.e., CDAl of $\leq 150(P=0.02)$. While in group $2,17.7 \%(132 / 747)$ had a clinical remission with a CDAl-100 in $34.4 \%(257 / 747)$.

At the end of the maintenance phase, at week $52,36.4 \%$ (56/154) in Group 2a and 39\% (60/154) in Group 2b achieved clinical remission, as compared to $21.6 \%$ (33/153) in Group 2c $(P<0.001$ and $P=0.004$ for the comparison of the two vedolizumab groups, respectively, with placebo).

At week 52, the fistula closure rate in Group $2 \mathrm{a}$ and $2 \mathrm{~b}$ was $22.7 \%(5 / 22)$ and $41.2 \%(7 / 17)$ compared to $11.1 \%$ (2/18) in Group 2c $(\mathrm{P}=0.32$ and $\mathrm{P}=0.03$ respectively).

Compared to placebo, Vedolizumab was associated with a higher rate of serious adverse events $(24.4 \%$ vs. $15.3 \%$ ), infections ( $44.1 \%$ vs. $40.2 \%)$, and serious infections $(5.5 \%$ vs. $3.0 \%)$.

At the beginning of the maintenance phase, $12 \%$ (57/461) of Vedolizumab responders (Group 2 of NCT00783692 trial) had $\geq 1$ active draining fistula, which was randomly assigned to receive either IV Vedolizumab (300 mg) every 4 weeks (22 cases) or every 8 weeks (17 cases) or placebo (18 cases) until week 52 . Note $79 \%$ (45/57) had perianal draining Crohn's fistula. Of which, 32 were allotted in Vedolizumab treated group, while 13 were in the placebo group.

By Week 14, 28\% (11/39) of Vedolizumab-treated patients compared with $11 \%(2 / 18)$ of placebo treated patients (absolute risk reduction [ARR] 95\% confidence interval [Cl], -11.4 to 43.9 ) achieved fistula closure. Corresponding rates at Week 52 were $31 \%(12 / 39)$ and $11 \%(2 / 18)$ (ARR: $19.7 \%$; 95\% Cl, -8.9 to 46.2$)$.

Similar results were observed in the patients with only perianal fistulae, $34 \%(11 / 32)$ in the Vedolizumabtreated patients compared to $15 \%(2 / 13)$ in the placebo group. Corresponding values at Week 52 were $31 \%$ (10/32) in the Vedolizumab treated while $11 \%(2 / 13)$ in the placebo group [ARR: $19.7 \%$; $95 \% \mathrm{Cl},-8.9$ to 46.2 ].

TABLE 5: Clinical Studies on the Management of Perianal Crohn's Fistula Primarily by Biologicals or the Combination of Therapies

¥ Published date; CD (Crohn’s Disease); non-CD (Non-Crohn’s Disease); SQ (subcutaneous), Crohn's Disease Activity Index (CDAl), PDAI (Perianal Disease Activity Index); CRP (C-reactive protein); CLASSIC: Clinical assessment of Adalimumab Safety and efficacy Studied as Induction therapy in Crohn's disease; CHARM: Crohn's Trial of the Fully Human Antibody Adalimumab for Remission Maintenance; RCT (randomized controlled trial)

\section{Conclusions}

To conclude, chronic seton therapy should be the primary approach, especially if the patient has a perianal abscess, supported by the low incidence of reintervention, recurrent abscess formation, side-branching of the fistulous tract, preservation of the fistulous tract's patency, and cost-effectiveness. The significant disadvantages of seton therapy are the discomfort and the time it takes to achieve stability. 
healing rate of perianal Crohn's fistula compared to placebo, but the major disadvantage associated with anti-TNF as sole therapy is high re-intervention rate, prolong maintenance therapy, high recurrence rate, and severe side effects. The efficacy of adalimumab and certolizumab pegol for the healing or closure of the perianal fistula closure has not been established in the clinical trials since the statistical significance is lacking compared to placebo. The efficacy of vedolizumab, albeit significantly lower but statistically significant for the remission of the perianal Crohn's fistula, is counterbalanced by the severe adverse reaction associated with its use. Therefore the use of either therapy for the sole purpose of fistula healing or closure in case of Crohn's disease would be futile.

We hypothesize that the two aspects should be addressed concomitantly to increase the rate of fistula closure. First, the seton should be used as initial therapy to maintain the tract's patency to allow the abscess's drainage and minimize the intestinal flora colonization within the tract mucosa, thereby leukocytic infiltration and propagation of inflammation within the tract. The absorbable seton could be used instead of non-absorbable. The second aspect that has to be considered is that we should target the initial stimulation of the Th1/Th17 mediated hypersensitivity instead of a factor/cytokine involved in the mediation of the inflammation. Although the unknown antigen triggering such hypersensitivity is not clear, we could target the RORY-T (transcription factor involved in activation of Th17 cells) and the T-bet (transcription factor involved in activation of Th17 cells) within the GI mucosa by a novel target immune therapy.

\section{Additional Information \\ Disclosures}

Conflicts of interest: In compliance with the ICMJE uniform disclosure form, all authors declare the following: Payment/services info: All authors have declared that no financial support was received from any organization for the submitted work. Financial relationships: All authors have declared that they have no financial relationships at present or within the previous three years with any organizations that might have an interest in the submitted work. Intellectual property info: All the images included in the review article. Other relationships: All authors have declared that there are no other relationships or activities that could appear to have influenced the submitted work.

\section{References}

1. Kelly ME, Heneghan HM, McDermott FD, Nason GJ, Freeman C, Martin ST, Winter DC: The role of loose seton in the management of anal fistula: a multicenter study of 200 patients. Tech Coloproctol. 2014, 18:915-9. 10.1007/s10151-014-1186-0

2. Dahlhamer JM, Zammitti EP, Ward BW, Wheaton AG, Croft JB: Prevalence of inflammatory bowel disease among adults aged $\geqslant 18$ years-United States, 2015. MMWR Morb Mortal Wkly Rep. 2015, 65:1166-1169. 10.15585/mmwr.mm6542a3

3. Nguyen GC, Chong CA, Chong RY: National estimates of the burden of inflammatory bowel disease among racial and ethnic groups in the United States. J Crohns Colitis. 2014, 8:288-295. 10.1016/j.crohns.2013.09.001

4. Malarcher CA, Wheaton AG, Liu Y, Greenlund SF, Greenlund SJ, Lu H, Croft JB: Hospitalizations for Crohn's disease-United States, 2003-2013. MMWR Morb Mortal Wkly Rep. 2017, 66:377-381. 10.15585/mmwr.mm6614a1

5. Xu F, Liu Y, Wheaton AG, Rabarison KM, Croft JB: Trends and factors associated with hospitalization costs for inflammatory bowel disease in the United States. Appl Health Econ Health Policy. 2019, 17:77-91. 10.1007/s40258-018-0432-4

6. Schwartz DA, Tagarro I, Díez MC, Sandborn WJ: Prevalence of fistulizing Crohn's disease in the United States: estimate from a systematic literature review attempt and population-based database analysis. Inflamm Bowel Dis. 2019, 25:1773-1779. 10.1093/ibd/izz056

7. Molendijk I, Nuij VJ, van der Meulen-de Jong AE, van der Woude CJ: Disappointing durable remission rates in complex Crohn's disease fistula. Inflamm Bowel Dis. 2014, 20:2022-8. 10.1097/MIB.0000000000000148

8. Eglinton TW, Barclay ML, Gearry RB, Frizelle FA: The spectrum of perianal Crohn's disease in a populationbased cohort. Dis Colon Rectum. 2012, 55:773-7. 10.1097/DCR.0b013e31825228b0

9. Bailey \& Love's Short Practice of Surgery, 26th Edition . Williams N, O’Connell PR (ed): CRC Press, Boca Raton; 2012.

10. Wasmann KA, de Groof EJ, Stellingwerf ME, et al.: Treatment of perianal fistulas in Crohn's disease, seton versus anti-TNF versus surgical closure following anti-TNF [PISA]: a randomised controlled trial. J Crohns Colitis. 2020, 14:1049-1056. 10.1093/ecco-jcc/jjaa004

11. Viganò C, Losco A, Caprioli F, Basilisco G: Incidence and clinical outcomes of intersphincteric abscesses diagnosed by anal ultrasonography in patients with Crohn's disease. Inflamm Bowel Dis. 2011, 17:2102-8. 10.1002/ibd.21596

12. Beaugerie L, Seksik P, Nion-Larmurier I, Gendre J-P, Cosnes J: Predictors of Crohn's disease . Gastroenterology. 2006, 130:650-6. 10.1053/j.gastro.2005.12.019

13. Raslan SM, Aladwani M, Alsanea N: Evaluation of the cutting seton as a method of treatment for perianal fistula. Ann Saudi Med. 2016, 36:210-5. 10.5144/0256-4947.2016.210

14. Sartor R: Mechanisms of disease: pathogenesis of Crohn's disease and ulcerative colitis . Nat Rev Gastroenterol Hepatol. 2006, 3:390-407. 10.1038/ncpgasthep0528

15. Panés J, Rimola J: Perianal fistulizing Crohn's disease: pathogenesis, diagnosis and therapy . Nat Rev Gastroenterol Hepatol. 2017, 14:652-664. 10.1038/nrgastro.2017.104

16. Parks AG, Gordon PH, Hardcastle JD: A classification of fistula-in-ano. Br J Surg. 1976, 63:1-12. 
17. American Gastroenterological Association: American Gastroenterological Association medical position statement: perianal Crohn's disease. Gastroenterology. 2003, 125:1503-7. 10.1016/j.gastro.2003.08.024

18. Memon AA, Murtaza G, Azami R, Zafar H, Chawla T, Laghari AA: Treatment of complex fistula in ano with cable-tie seton: a prospective case series. ISRN Surg. 2011, 2011:636952.

19. Dudukgian H, Abcarian H: Why do we have so much trouble treating anal fistula? . World J Gastroenterol. 2011, 17:3292-6. 10.3748/wjg.v17.i28.3292

20. Ritchie RD, Sackier JM, Hodde JP: Incontinence rates after cutting seton treatment for anal fistula . Colorectal Dis. 2009, 11:564-71.

21. Van Tets WF, Kuijpers JH: Seton treatment of perianal fistula with high anal or rectal opening . Br J Surg. 1995, 82:895-7.

22. Thornton M, Solomon MJ: Long-term indwelling seton for complex anal fistulas in Crohn's disease . Dis Colon Rectum. 2005, 48:459-63. 10.1007/s10350-004-0830-6

23. Van Der Hagen SJ, Baeten CG, Soeters PB, Beets-Tan RG, Russel MM, van Gemert WG: Staged mucosal advancement flap for the treatment of complex anal fistulas: pretreatment with noncutting Setons and in case of recurrent multiple abscesses a diverting stoma. Colorectal Dis. 2005, 7:513-518.

24. Galis-Rozen E, Tulchinsky H, Rosen A, et al.: Long-term outcome of loose seton for complex anal fistula: a two-centre study of patients with and without Crohn's disease. Colorectal Dis. 2010, 12:358-62.

25. Fazio VW: Complex anal fistulae. Gastroenterol Clin North Am. 1987, 16:93-114.

26. Papaconstantinou I, Kontis E, Koutoulidis V, Mantzaris G, Vassiliou I: Surgical management of fistula-inano among patients with Crohn's disease: analysis of outcomes after fistulotomy or seton placement-singlecenter experience. Scand J Surg. 2017, 106:211-215. 10.1177/1457496916665763

27. Lim CH, Shin HK, Kang WH, et al.: The use of a staged drainage seton for the treatment of anal fistulae or fistulous abscesses. J Korean Soc Coloproctol. 2012, 28:309-14. 10.3393/jksc.2012.28.6.309

28. Buchanan GN, Owen HA, Torkington J, Lunniss PJ, Nicholls RJ, Cohen CR: Long-term outcome following loose-seton technique for external sphincter preservation in complex anal fistula. Br J Surg. 2004, 91:47680 .

29. Seow-Choen F, Nicholls RJ: Anal fistula. Br J Surg. 1992, 79:197-205.

30. Drager LF, Andrade MN, Conceicao SA, Cunha-Melo JR: Perianal fistula: retrospective study of surgical treatment of 241 cases. Acta Cir Bras. 1998, 13:23-8. 10.1590/S0102-86501998000200007

31. Sileri P, Cadeddu F, D'Ugo S, et al.: Surgery for fistula-in-ano in a specialist colorectal unit: a critical appraisal. BMC Gastroenterol. 2011, 11:120. 10.1186/1471-230X-11-120

32. Chung W, Ko D, Sun C, et al.: Outcomes of anal fistula surgery in patients with inflammatory bowel disease . Am J Surg. 2010, 199:609-13. 10.1016/j.amjsurg.2010.01.007

33. Present DH, Rutgeerts $\mathrm{P}$, Targan S, et al.: Infliximab for the treatment of fistulas in patients with Crohn's disease. N Engl J Med. 1999, 340:1398-405. 10.1056/NEJM199905063401804

34. Farrell RJ, Shah SA, Lodhavia PJ, et al.: Clinical experience with infliximab therapy in 100 patients with Crohn's disease. Am J Gastroenterol. 2000, 95:3490-7.

35. Luna-Chadid M, Pérez Calle JL, Mendoza JL, et al.: Predictors of response to infliximab in patients with fistulizing Crohn's disease. Rev Esp Enferm Dig. 2004, 96:379-81. 10.4321/s1130-01082004000600003

36. Sands BE, Anderson FH, Bernstein CN, et al.: Infliximab maintenance therapy for fistulizing Crohn's disease . N Engl J Med. 2004, 350:876-85. 10.1056/NEJMoa030815

37. Yarur AJ, Kanagala V, Stein DJ, et al.: Higher infliximab trough levels are associated with perianal fistula healing in patients with Crohn's disease. Aliment Pharmacol Ther. 2017, 45:933-940.

38. Hanauer SB, Sandborn WJ, Rutgeerts P, et al.: Human anti-tumor necrosis factor monoclonal antibody (adalimumab) in Crohn's disease: the CLASSIC-I trial. Gastroenterology. 2006, 130:323-33. 10.1053/j.gastro.2005.11.030

39. Sandborn WJ, Hanauer SB, Rutgeerts P, et al.: Adalimumab for maintenance treatment of Crohn's disease: results of the CLASSIC II trial. Gut. 2007, 56:1232-9. 10.1136/gut.2006.106781

40. Sandborn WJ, Rutgeerts P, Enns R, et al.: Adalimumab induction therapy for Crohn disease previously treated with infliximab: a randomized trial. Ann Intern Med. 2007, 146:829-38. 10.7326/0003-4819-146-12200706190-00159

41. Colombel JF, Schwartz DA, Sandborn WJ, et al.: Adalimumab for the treatment of fistulas in patients with Crohn's disease. Gut. 2009, 58:940-8. 10.1136/gut.2008.159251

42. Sandborn WJ, Feagan BG, Stoinov S, et al.: Certolizumab pegol for the treatment of Crohn's disease . N Engl J Med. 2007, 357:228-38. 10.1056/NEJMoa067594

43. Schreiber S, Khaliq-Kareemi M, Lawrance IC, et al.: Maintenance therapy with certolizumab pegol for Crohn's disease. N Engl J Med. 2007, 357:239-50. 10.1056/NEJMoa062897

44. Schreiber S, Lawrance IC, Thomsen OØ, et al.: Randomised clinical trial: certolizumab pegol for fistulas in Crohn's disease - subgroup results from a placebo-controlled study. Aliment Pharmacol Ther. 2011, 33:18593.

45. Sandborn WJ, Feagan BG, Rutgeerts P, et al.: Vedolizumab as induction and maintenance therapy for Crohn's disease. N Engl J Med. 2013, 369:711-21. 10.1056/NEJMoa1215739

46. Feagan BG, Schwartz D, Danese S, Rubin DT, Lissoos TW, Xu J, Lasch K: Efficacy of vedolizumab in fistulising Crohn's disease: exploratory analyses of data from GEMINI 2. J Crohns Colitis. 2018, 12:621-626. 10.1093/ecco-jcc/jiy019

47. de Groof EJ, Buskens CJ, Ponsioen CY, et al.: Multimodal treatment of perianal fistulas in Crohn's disease: seton versus anti-TNF versus advancement plasty (PISA): study protocol for a randomized controlled trial. Trials. 2015, 16:366. 10.1186/s13063-015-0831-x

48. Fortea-Ormaechea JI, González-Lama Y, Casis B, et al.: Adalimumab is effective in long-term real life clinical practice in both luminal and perianal Crohn's disease. The Madrid experience. Gastroenterol Hepatol. 2011, 34:443-8. 10.1016/j.gastrohep.2011.04.001

49. Lichtiger S, Binion DG, Wolf DC, et al.: The CHOICE trial: adalimumab demonstrates safety, fistula healing, improved quality of life and increased work productivity in patients with Crohn's disease who failed prior infliximab therapy. Aliment Pharmacol Ther. 2010, 32:1228-39. 